\title{
INFLUENCE OF IMMIGRANTS ON THE ENTREPRENEURSHIP DEVELOPMENT IN THE HOST COUNTRIES
}

\author{
Roman STAKANOV 1 \\ Institute of International Relations of Taras Shevchenko National University of Kyiv, Ukraine
}

\begin{abstract}
Research subject. In the economic literature the question under discussion is whether the migrant entrepreneurs are more active in business and self-employment than native, as well as what role government should play when receiving entrepreneur migrants. This paper should provide answers to the abovementioned questions, and give recommendations to the governments of the host countries on migration policy taking into account the results obtained. The purpose of this article is to investigate the entrepreneurial activity of immigrants in the host countries, and to analyze the migration policy of the host countries concerning migrant entrepreneurs. Survey methodology. We used theoretical and empirical research methods; provided analysis of recent publications of scientists on the discussed subject, comparing the results obtained with statistical data, and provided practical recommendations based on survey results. Results. Migrants are often seen as those who have a considerable propensity for entrepreneurial activity. Proponents of this point of view suggested the case of migrant entrepreneurs' success in China and the United States, arguing that workers may not need work with a formalized salary because of theirs entrepreneurial independence. Despite the theoretical basis of higher business activity, empirical studies of entrepreneurial activity of migrants are not clear. One of the arguments, which determine the attitude towards migrants, as more capable of entrepreneurship, based on the selectivity. The fact that a person has taken a relatively risky decision to migrate, ensure its stronger business activity and, consequently, the share of businessmen in this category of the labor force must be greater than the average for the country of immigration. Host governments often use both specific and general business support programs. Specific programs include the expansion of linguistic knowledge, business skills, and professional contacts of migrants' labor force importer countries. Migrant entrepreneurs, especially when they work in the field of innovation or in sectors with high added value, play a great potential role in economic growth and competitiveness of host countries. Such migration can make a significant contribution in supporting economic activity and contribute to the social adaptation of migrants in destination countries. Conclusion. Entrepreneur migrants can help to stabilize the labor market, which will benefit both migrant workers and local residents. Given the fact that not all immigrants have the appropriate skills, ability, desire and opportunity to be entrepreneurs in the host countries, the introduction of a single incentive policy for immigration only entrepreneurs and investors, without taking into account the needs of the labor market seems to be counterproductive.
\end{abstract}

Key words: international migration, entrepreneurship, migrants, migration policy, OECD.

JEL Classification: F22, L26, F22, F22, F02

\section{1. Вступмение}

Принимающие мигрантов страны всегда заинтересованы в наиболее качественном человеческом ресурсе. Большинство развитых стран испытывают потребность в импорте иностранной рабочей силы в силу Аемографических причин или же несоответствия спроса и преАложения на национальном рынке рабочей силы. ОАнако если иммиграция малоквалифицированной рабочей силы является постоянным преАметом рестрикционной миграционной поли- тики, то аАмиссия работников высокой квалификации, инвесторов и преАпринимателей традиционно поощряется принимающими странами. В Аанной статье будет проанализировано эффективность использования преАпринимательского ресурса иммигрантов в странах пребывания, имеют ми объективные преимущества мигранты по сравнению с местными жителями в бизнес среде, а также какие инструменты используются странами иммиграции Аля оптимизации эффекта Аеятельности предпринимателей иммигрантов.

\footnotetext{
Corresponding author:

${ }^{1}$ Department of World Economy and International Economic Relations,

Institute of International Relations of Taras Shevchenko National University of Kyiv.

E-mail: roman.stakanov@gmail.com
} 
В экономической митературе Аискутируется вопрос о том, явмяются ми мигранты преАприниматели более предрасположенными к бизнесу и самостоятельной занятости в силу своей большей экономической активности, а также какую роль Аолжно играть правительство при приеме иммигрантов. Проведенное исследование должно Аать ответы на вышеприведенные вопросы, а также Аать рекоменАации правительствам принимающих стран с учетом полученных результатов.

Целью Аанной статьи явмяется исследование преАпринимательской активности иммигрантов в странах пребывания, а также анализ миграционной политики принимающих стран касательно преАпринимателей мигрантов.

В работе использованы теоретические и эмпирические методы исследования, которые предусматривают анализ последних публикаций ученых по теме статьи, сравнение полученных результатов с Аанными статистики, а также обобщение полученных данных в виде практических рекомендаций.

\section{2. Анализ послеАних публикаций}

Международная трудовая миграция, глобальный и региональные рынки труда, а также миграционная политика отдельных стран и регионов, в том числе и стран ОЭСР, исследовались рядом ученых, среди которых, в первую очередь, следует выдемить Аж. Борхаса, А. ГайАуцкого, С. Аринквотера, И. Ивахнюка, Э. Аибанову, А. Малиновскую, С. Метемева, А. Рата, А. Румянцева, А. Старка, А. Уинтерса, А. Фикиппенко, Аж. Фиореса, Р. Чами. ОтАельно вопросами взаимосвязи миграции, преАпринимательства и экономического развития в странах иммиграции и эмиграции занимахись М. Аезидерио, В. Науде, К. МарчанА, М. Сигем. Также значитемьное внимание Аанной проблематике было уделено в отчетах межАународных организаций, таких как МОП и ОЭСР, а также отдельных институтов региональных интеграционных объединений, в частности Европейской Комиссией.

Иммиграционный приток имеет потенциально положительное влияние на принимающие страны. В то же время, не все страны автоматически выигрывают от миграционных процессов. В связи с этим, Г. де Хaac (de Haas, 2010) предостерегает от упрощающих преАположений об автоматическом влиянии миграции на экономическое развитие. Большое значение А^я эффективности такой взаимосвязи имеет экономическая политика государства.

Мигранты зачастую рассматриваются, как такие кто имеют значитемьную склонность к преАпринимательской деятельности. Сторонники этой точки зрения отмечают успех предпринимателей мигрантов в Китае и США, утвержАая, что мигранты могут не нуждаться работе с формализованной оплатой труда. Например, С. Гиулиетти (Giulietti, 2011) отмечает, что в таких успешных развивающихся как Китай, 25\% мигрантов самозанятыми. А. Саксениан (Saxenian, 2006) выделил значительную роль иммигрантов в развитии Силиконовой Аолины в США, гАе около оАной трети технологического бизнеса находилось в собственности иммигрантов.

Аж. Хант и М. Гаузиер (Hunt, 2009) обнаружики, что иммигранты были владельцами 24\% патентов в США, что в Ава раза превышает их Аолю в структуре населения страны. С Аругой стороны, работа А. Херта (Hart, 2009) показаца, что в сфере высокотехнологического предпринимательства США мигранты не явмяются более активными в регистрации патентов, чем местные жители, а предыдущие исследования, по мнению Херта, переоценивали значение иммигрантов Аля Аанного сегмента экономики. Аналогично, Ф. Невим [W113] исследуя ситуацию со стартапами в Канаде не нашем подтверждения тому, что такие показатели как объем продаж и объем прибыли новых преАприятий зависят от того владеют ими иммигранты или местные жители.

\section{3. Резумьтаты исследования автора}

Несмотря на теоретическое обоснование более высокой преАпринимательской активности, эмпирические исследования предпринимательской активности мигрантов не однозначны. Исследование ОЭСР (OECD, 2011) указывает на то, что мигранты явмяются более активными по сравнению с местным насемением всего в 13 из 25 исследуемых стран. Также в странах со значительными объемами иммигрантов, таких как Германия, Итамия, Испания, Швейцария или Нидерланды мигранты имеют значительно меньшую склонность к самостоятельной занятости, чем местные жители. В скучае с иммиграцией в Германии, У. Брикси (Brixy, 2013) отмечает, что мигранты в меньшей степени скмонны считать, что они имеют необходимые качества Аля открытия бизнеса. Также M. Янсен, исследуя случай Нидерландов (Jansen, 2003) обнаружил, что уровень преАпринимательской активности среАи местного населения, как и турецких иммигрантов, вАвое выше аналогичных показателей иммигрантов из Марокко, Суринама и Антильских островов.

ОАин из аргументов, который опредемяет отношение к мигрантам, как к более склонным к преАпринимательству по сравнению с местными жителями, базируется на селективности. Тот факт, что мицо приняло относительно рисковое решение о миграции, говорит о более высокой ее деловой активности, а, следовательно, склонность к предпринимательству в Аанной категории трудовых ресурсов Аолжна быть больше, чем в среднем по стране иммиграции (Neville, 2014). С Аругой стороны, иммигранты в большей степени преАставлены среАи самозаня- 
тых поскольку они могут быть исключены из более формальных возможностей трудоустройства, таким образом, они вынуждены переходить в сегмент самозанятости поскольку испытают потребность в более креативном решении проблемы поиска финансовых ресурсов (Brixy, 2013). ОАним из преимуществ мигрантов преАпринимателей явмяется их более развитые социальные межАународные связи, что позвомяет преАприятиям мигрантов быть более успешными при осуществлении внешнеэкономических операций (Naude, 2015).

В рамках проведенного в 2012 г. Исследования Гцобального мониторинга преАпринимательства (Vorderwuelbecke, 2012) бымо обнаружено, что общий уровень стратапов среди иммигрантов и местного населения находится на одном уровне, хотя он и варьируется в разных странах, как Аля мигрантов, так и Аля местной рабочей силы. ИсслеАование показало, что Аишь 1,8\% мигрантов в первом покомении в Африке к югу от Сахары были задействованы в учреждении бизнеса. В то же время Аанный показатель в США и Западной Европе колеблется в районе 10-11\%. ОАнако, А. Вордервуелбекке (Vorderwuelbecke, 2012) также обнаружил, что в среднем преАприятия, которые находятся в собственности мигрантов, Аолжны создать 10 и более рабочих мест в течение 5 мет. В то время как аналогичный показатель среди местных жителей составмяет мишь 14\%. Около 16\% высокотехнологичных фирм в США находились в собственности мигрантов (Naude, 2015). А. Саксениан (Saxenian, 2006) утвержАац, что развитие высокотехнологичного сектора и инновационных кластеров в таких странах как Китай, Индия и Тайвань происходили вслеАствие реэмиграции транснационамьных предприниматемей из США.

К типичным проблемам преАпринимателей мигрантов добавляется сложность в получении креАитов официальных финансовых институтов. Амя того чтобы побороть эти преграды правительства принимающих стран часто используют одновременно специфические и общие программы поААержки бизнеса. Специфические целевые программы Аля преАпринимателей иммигрантов предусматривают расширение языковых знаний, бизнес умений, а также профессионамьных контактов. Также Аовольно распространенным явмяются меры по улучшению кредитоспособности иммигрантов и их бизнеса, а также облегчение Аоступа к капитальным ресурсам А^я созАания и развития преАприятий. Такие инициативы могут положительно повлиять как на самих мигрантов, так и на развитие регионов их концентрации, а также сосеАних регионов (Desiderio, 2014).

Еще оАной проблемой Аля преАприятий мигрантов является тот факт, что их бизнес в среАнем Аемонстрирует более низкие показатели Алительности функционирования после основания по сравнению с местными преАприятиями. Кроме того, в большинстве стран ОЭСР преАприятия мигрантов концентрируются в секторах с низкой добавленной стоимостью. Специфические препятствия в деятельности таких преАприятий имеют тенАенцию сокращаться с ростом срока проживания мигранта в принимающей стране (Desiderio, 2014).

Недостаток уровня финансирования явмяется главным препятствием Аля развития малого и среАнего преАпринимательства, как Аля преАприятий иммигрантов, так и Аля местных владельцев. ОАнако Аля иммигрантов Аанная проблема усугубляется наличием менее Алительной кредитной истории в принимающей стране, а наличие креАитной истории в стране происхождения, в силу отсутствия механизмов обмена такой информацией, не может им помочь в стране пребывания. Также довольно часто доступ к бизнес среде является обусловленным требованием к капиталу. Таким образом, ограниченный Аоступ к кредитам официальных финансовых институтов стимулирует преАприятия иммигрантов оставаться в секторах экономики с низкой Аобавленной стоимостью, гАе барьеры Аля доступа на рынок существенно ниже. К таким секторам, в частности, относятся строительство, розничная торговмя, общественное питание и Ар. ПреАприниматели мигранты в большей степени, чем местные жители полагаются на собственные, семейные ресурсы и среАства своего сообщества. Это, в свою очередь, формирует условия Аля мокализации бизнеса иммигрантов в рамках их Аиаспор и ограничивает возможности Аля развития и расширения деятельности за ее пределы. С целью устранения такого финансового барьера, одним из видов целевых программ помощи мигрантам-предпринимателям явцяются меры по содействию Аоступа к кредитам. Такие меры предусматривают предоставмение гарантий и знаков качества. Например, в Испании Муниципальный Институт экономики и рынка труда города Террасса ставит печати качества на бизнес-пианы, которые быми написаны мигрантами в сотрудничестве с Институтом (Desiderio, 2014).

С 2000 г. страны ОЭСР активно вводили новую или реформировали существующие политики привцечения мигрантов преАпринимателей и инвесторов. Такая целевая политика была в первую очередь направлена на аАмиссию иммигрантов со значительным человеческим и финансовым капиталом, таким образом, повышая конкурентоспособность и стимулируя экономический рост принимающих стран. В отдельных странах такая политика имела целью стимулировать мигрантов поселяться и инвестировать в отАельные зоны, способствуя экономическому развитию Аепрессивных регионов, а также развитию Аеловых и технологических кластеров. Например, Австралия и Канада имеют программы, которые переАают отАельные полномочия по иммиграции вмадельцев бизнеса свои штатам, территориям или 
провинциям. ОАнако, среди стран ОЭСР мишь незначительная часть иммигрантов попала в страну назначения, пользуясь специальными разрешениями Аля миграции с целью осуществления преАпринимательской деятельности. Большинство мигрантов, которые основали преАприятия в принимающих странах, сначала въехали через Аругие миграционные потоки, такие как занятость или учебы (Desiderio, 2014).

КАючевые страны иммиграции, такие как Канада, Австрамия, США, быми оАними из первых, кто начали принимать меры по привлечению талантмивых иностранцев с преАпринимательскими способностями и продолжали это Аелать и в кризисный период после 2008 (Desiderio, 2014). В рамках ЕС мигранты составмяют значитемьный объем потенциальных преАпринимателей, которые, однако, в большей степени подпадают род разные виды ограничений в своей Аеятельности (законодательные, кумьтурные, мингвистические). Это, в свою очереАь, снижает эффективность их Аеятельности и требует стимулирующего вмешательства со стороны государственных и надгосударственных органов (European Commission, 2016).

Содействие преАпринимательству предусмотрено Стратегией Европа-2020, цемью которой явмяется создание условий Аля разумного, устойчивого и инклюзивного роста в ЕС. В рамках Стратегии был принят Пиан Аействий Предпринимательство-2020. Целью Аанного Пиана явмяется стимулирование создания нового бизнеса, а также формирование значительно более благоприятной среАы Аля функционирования уже существующего. ОтАельное обязательства в рамках Пиана действий предусматривается по содействию преАпринимательства среАи мигрантов, которые уже присутствуют на территории ЕС. Аокументом предусмотрено проведение бизнес тренингов и наставничество, а также открытие Аоступа Аля иммигрантов кмючевых структур подАержки. Европейская Комиссия определяет мучшую практику с целью содействия и поААержки преАпринимательской Аеятельности мигрантов и финансирует пикотные проекты с целью ее распространения (European Commission, 2016).

ОтАельными странами ЕС была введена политика, специально направленная на привлечение в страну мигрантов преАпринимателей, в том числе через введение специального визового регулирования А^я Аанной категории мигрантов. Такие мигранты рассматривались, например, такими странами как Нидерланды и Германия (OECD, 2011), в качестве потенциального Арайвера местной экономики и соответственно они получали режим максимацьного благоприятствования со стороны правительств. Такая политика явцяется селективным отбором, в основе которого межит принцип принятия именно тех мигрантов, которые прибывая в страну, приносят вместе с собой Аостаточное количество финансового или человеческого капитала, таким образом, обеспечивая Аостаточный вклаА в экономику принимающей страны (Naude, 2015).

Общие программы поААержки преАпринимателей явмяются Аоступными Аля всего населения, проживающего в стране, они также могут способствовать развитию преАпринимательства мигрантов, в том случае, если иммигранты имеют к ним свободный Аоступ. Такие программы ориентируются на предоставление более совершенных услуг подАержки бизнеса, таких как инкубаторы Аля высокотехнологичных стартапов, а не целевой поААержки иммигрантов. Оба способа поддержки могут выступать взаимодополняющими механизмами. Такие программы также Аолжны быть стать составной частью более широких стратегий по созАанию среАы бцагоприятной Амя предпринимательства (Desiderio, 2014).

В феврале 2016 состоялась Европейская конференция по преАпринимательской Аеятельности мигрантов. На ней отмечалось, что мигрантам зачастую не хватает знаний и информации о культуре бизнеса, регуляторной среде в стране назначения. ААминистративные и социокультурные сложности могут нивелировать потенциальные перспективы роста новосозданного бизнеса, что, в свою очередь, уменьшает положительное влияние деятельности мигрантов преАпринимателей на экономическое развитие страны-импортера рабочей силы. Таким образом, на конференции быма подАержана позиция о необходимости развития схем по цемевой поАдержке мигрантов преАпринимателей в Европе (European Commission, 2016).

\section{4. Выводы}

Иммиграция преАпринимателей, в первую очереАь, когАа они работают в сфере инноваций или в отраслях с высокой Аобавленной стоимостью, имеет большое потенциальное значение Аля экономического роста и обеспечения конкурентоспособности принимающих стран. Такая миграция может сделать значительный вклаА в поААержку экономической активности, а также способствовать социальной аАаптации мигрантов в странах пребывания. Несмотря на то, что значительная часть стран-импортеров рабочей силы все еще не поборола послеАствия экономического кризиса, преАприниматели мигранты могут помочь в стабилизации рынка труда, что принесет пользу, как рабочим мигрантам, так и местным житемям.

ОАнако проведенные исследования указывают на то, что нельзя полностью отожАествцять прирост иммиграции с ростом преАприниматемьства во всех принимающих странах. Вполне очевидным представмяется, что преАпринимательство и самозанятость мигрантов не всегАа происходит от их желания, а Аостаточно часто явмяется вынужАенной необходимостью. В то же время, ряА Аанных указывают на то, 
что мигранты проявмяют существенно более высокую инновационную активность в отАельных странах, в частности в США. Роль иммигрантов также явмяется весомой Амя развития высокотехнологичных, биотехнических, венчурных компаний. При этом проведенные исследования четко не указывают на то, что количество новых товаров или услуг в большей степени производятся инновационными преАприниматемями мигрантами по сравнению с местными житемями.

Целевые программы подАержки иммигрантов-предпринимателей явмяются весомым способом обеспечения равных возможностей Аля иммигрантов, которые начинают, продолжают или расширяют свой бизнес, поскомьку они помогают нивемировать неравные условия, в которые они попадают, конкурируя с местными предпринимателями. Благодаря таким программам Аостигается широкая экономическая интеграция, что, в конце концов, позволяет мигрантам получить Аоступ, в том чисме и к общим программам поААержки преАпринимателей в принимающих странах.

Наиболее эффективным способом подАержки бизнеса мигрантов явмяется объеАинение усилий различных субъектов рынка. К таким институтам можно отнести национальное правительство, местные органы власти, государственные учреждения ответственные за размичные аспекты национальной экономической политики (в частности в сфере образования, науки, экономической, намоговой и миграционной политик), отдельные негосударственные учрежАения, такие как торгово-промышиенные палаты, профсоюзы, неправительственные организации, а также преАставитекей бизнес среАы. Такое частно-государственное партнерство способствует уменьшению государственных расходов на поААержку бизнеса, а также на специальные программы по интеграции мигрантов.

С учетом того, что не все иммигранты обладают соответствующими способностями, умениями, желанием и возможностями быть преАприниматемями в принимающих странах, ввеАение отдельной стимулирующей политики Аля иммиграции исключительно преАпринимателей и инвесторов, без учета потребностей рынка труаа (в том числе и структурных потребностей в низкоквалифицированной рабочей силе в Аолгосрочной перспективе) преАставляется автору контрпродуктивным.

\section{References}

Brixy, U., Sternberg, R., Vorderwlbecke, A. (2013). Business start-ups by migrants. IAB Brief Report 25. Nrnberg: Institute for Employment Research.

Desiderio, M. (2014). Migrant Entrepreneurship: An Overview Retrieved from http://www.immigrationresearchinfo.org/report/migration-policy-institute/policies-support-immigrant-entrepreneurship

Giulietti, C., Ning, G., Zimmermann, K. (2011). Self-employment of rural-to-urban migrants in China. IZA Discussion Paper No. 5805. Bonn: Institute for the Study of Labor. European Commission (2016). Migrant entrepreneurs. Retrieved Septmber 21, 2016, from https://ec.europa.eu/growth/smes/promotingentrepreneurship/we-work-for/migrants_en

de Haas, H. (2010). Migration and development: A theoretical perspective. International Migration Review, 44(1):227-264.

Hart, D. (2009). High-tech immigrant entrepreneurship in the us: A preliminary report. Industry Studies Annual Conference, 20 May, Chicago.

Hunt, J. and Gauthier-Loiselle, M. (2009). How much does immigration boost innovation? IZA Discussion Paper No. 3921. Bonn: Institute for the Study of Labor.

Jansen, M., de Kok, J., van Spronsen, J., Willemsen, S. (2003). Immigrant entrepreneurship in the netherlands. Research Report H200304, SCALES

Naude, W., Siegel M., Marchand K. (2015). A Critical Review. Migration, Entrepreneurship and Development. Retrieved from http://ftp.iza.org/dp9284.pdf

Neville, F., Orse, B., Riding, A., Jung, O. (2014). Do young firms owned by recent immigrants outperform other young firms? Journal of Business Venturing, 29(1):55-71.

OECD (2011). Divided We Stand: Why Inequality Keeps Rising. Paris: Organization for Economic Development and Cooperation.

Saxenian, A. (2006). The new argonauts. Cambridge MA: Harvard University Press

Vorderwuelbecke, A. (2012). Global Entrepreneurship Monitor - 2012 Global Report, chapter Entrepreneurship and Migration, pages 42-50. Global Entrepreneurship Consortium. 


\section{Роман СТАКАНОВ}

\section{ВЛИЯНИЕ ИММИГРАНТОВ НА РАЗВИТИЕ ПРЕДПРИНИМАТЕЛЬСТВА В СТРАНАХ ПРЕБЫВАНИЯ}

Аннотация. Предмет исследования. В экономической литературе дискутируется вопрос о том, являются ли мигранты предприниматели более предрасположенными к бизнесу и самостоятельной занятости в силу своей большей экономической активности, а также какую роль должно играть правительство при приеме иммигрантов. Проведенное исследование должно дать ответы на вышеприведенные вопросы, а также дать рекомендации правительствам принимающих стран с учетом полученных результатов. Целью данной статьи является исследование предпринимательской активности иммигрантов в странах пребывания, а также анализ миграционной политики принимающих стран касательно предпринимателей мигрантов. Методология исследования. В работе использованы теоретические и эмпирические методы исследования, которые предусматривают анализ последних публикаций ученых по теме статьи, сравнение полученных результатов с данными статистики, а также обобщение полученных данных в виде практических рекомендаций. Результаты исследования автора. Мигранты зачастую рассматриваются, как такие кто имеют значительную склонность к предпринимательской деятельности. Сторонники этой точки зрения отмечают успех предпринимателей мигрантов в Китае и США, утверждая, что мигранты могут не нуждаться работе с формализованной оплатой труда. Несмотря на теоретическое обоснование более высокой предпринимательской активности, эмпирические исследования предпринимательской активности мигрантов не однозначны. Один из аргументов, который определяет отношение к мигрантам, как к более склонным к предпринимательству по сравнению с местными жителями, базируется на селективности. Тот факт, что лицо приняло относительно рисковое решение о миграции, говорит о более высокой ее деловой активности, а, следовательно, склонность к предпринимательству в данной категории трудовых ресурсов должна быть больше, чем в среднем по стране иммиграции. Правительства принимающих стран часто используют одновременно специфические и общие программы поддержки бизнеса. Специфические целевые программы для предпринимателей иммигрантов предусматривают расширение языковых знаний, бизнес умений, а также профессиональных контактов. Иммиграция предпринимателей, в первую очередь, когда они работают в сфере инноваций или в отраслях с высокой добавленной стоимостью, имеет большое потенциальное значение для экономического роста и обеспечения конкурентоспособности принимающих стран. Такая миграция может сделать значительный вклад в поддержку экономической активности, а также способствовать социальной адаптации мигрантов в странах пребывания. Выводы. Несмотря на то, что значительная часть стран-импортеров рабочей силы все еще не поборола последствия экономического кризиса, предприниматели мигранты могут помочь в стабилизации рынка труда, что принесет пользу, как рабочим мигрантам, такиместнымжителям.Сучетомтого, что невсеиммигранты обладаютсоответствующими способностями, умениями, желанием и возможностями быть предпринимателями в принимающих странах, введение отдельной стимулирующей политики для иммиграции исключительно предпринимателей и инвесторов, без учета потребностей рынка труда представляется автору контрпродуктивным. 